\title{
Paradigms of Intercultural Education Romanian Language for Foreigners
}

\author{
Ciobotaru Georgiana \\ Cross-Border Faculty, University „Dunărea de Jos” Galați, Romania
}

\begin{abstract}
Contemporary education presupposes a perpetual cultural metamorphosis, the borders being visibly blurred. The process of teaching the Romanian language as a foreign language presupposes, in equal measure, a paradigm shift, the emphasis shifting, thus, from the pattern of the native speaker to that of the foreign speaker with an important intercultural component. Often, communication contexts are perceived as areas of intersections of several cultures that involve, finally, mutations in the identity of each of the interlocutors. The intercultural dimension of the act of teaching-learning means a comparative approach of both one's own culture and that of the assimilated one. This paper aims to highlight the perspective from which can be developed that competence of intercultural communication in terms of foreign students, those who come to Romania to study the Romanian language for teaching reasons, to later attend university courses in the language mentioned. The current context is all the more challenging, as the online environment has become the exclusive space of the instructive process - educational, methods, procedures, tools used to be adapted to new situations of teaching - learning and development of linguistic and intercultural skills
\end{abstract}

Keywords: metamorphosis, intercultural, identity, intersection 